\title{
Assessment of the Particulate Matter Reduction Potential of Climbing Plants on Green Walls for Air Quality Management
}

\author{
$\mathrm{Na}$ Ra Jeong ${ }^{1 *}$, Jeong-Hee Kim ${ }^{2}$, Seung Won Han ${ }^{1}$, Jong-Cheol Kim ${ }^{3}$, and Woo Young Kim \\ ${ }^{1}$ Researcher, Urban Agriculture Division, National Institute of Horticultural \& Herbal Science, RDA, Wanju 55365, South Korea \\ ${ }^{2}$ Senior researcher, Urban Agriculture Division, National Institute of Horticultural \& Herbal Science, RDA, Wanju 55365, South Korea \\ ${ }^{3}$ Postdoctoral researcher, Urban Agriculture Division, National Institute of Horticultural \& Herbal Science, RDA, Wanju 55365, South Korea
}

\section{ABSTRACT}

Background and objective: To improve air quality, particulate matter (PM) can be reduced using green infrastructure. Therefore, in this study, we aimed to determine the particulate matter reduction potential of climbing plants used for green walls, an element of vertical green infrastructure.

Methods: A sealed chamber with controlled environmental variables was used to assess the PM reduction level caused by climbing plants. PM concentration in the plant chamber was measured after two and four hours of PM exposure, and the reduction potential was assessed based on the leaf area.

Results: Compared to the empty chamber (Control), the PM reduction speed per hour was higher in the plant chamber, which confirmed that climbing plants contribute to the reduction of PM in the air. The PM reduction speed immediately after exposure in the plant chamber was high, but this slowed over time. Additionally, PM has been continuously reduced in plants with large leaves. As a result of calculating the particulate matter reduction level based on leaf area, it was found that there was a difference by particle size. Actinidia arguta, Parthenocissus tricuspidata, Trachelospermum asiaticum, and Euonymus fortuneivar. radicans showed a high reduction effect. The trichomes on the leaf surface of Trachelospermum asiaticum were found to affect PM reduction.

Conclusion: PM adsorption on the leaf surface is an important factor in reducing its concentration. It was possible to compare different plants by quantifying the amount of PM reduction during a fixed time period. These results can be used as the basic data to select the plant species suitable for urban green walls in terms of PM reduction.

Keywords: green infrastructure, vines, leaf shape, trichome, Trachelospermum asiaticum

\section{Introduction}

Climate is a critical factor that affects air quality, and deteriorated air quality directly affects human health as well as the ecosystem, which ultimately affects the climate and human health in a feedback loop (WHO, 2013; Haase et al., 2014; Orru et al., 2017). Particulate matter is reported as the main environmental cause of 3 million premature deaths worldwide (WHO, 2016) and is known to cause respiratory diseases and cardiovascular diseases (Hussain et al., 2011; Oller and Oberdörster, 2016; Chalvatzaki et al., 2019).

Traffic emission is the main cause of air pollution comprised of particulate matter and gas pollutants such as carbon monoxide and nitrogen oxide (Abhijith et al., 2017; Li et al., 2016; Ortolani and Vitale, 2016; Kumar et al., 2018). Reducing emissions of pollutants would be the direct way to reduce exposure to air pollution, but there is a difficulty in actually managing air quality with just emission control strategies. Green infrastructure is considered one of the useful passive control systems for exposure to air pollution. Green infrastructure can reduce exposure by

This work was carried out with the support of research project of Rural Development Administration (PJ014270022021).

Received: June 1, 2021, Revised: July 6, 2021, Accepted: July 28, 2021

First author: Na Ra Jeong, jnr202@korea.kr, (D) https://orcid.org/0000-0002-0235-1424

*Corresponding author: Na Ra Jeong, jnr202@korea.kr, (D) https://orcid.org/0000-0002-0235-1424 
extending the distance between the emission source and receptor, promoting dilution and dispersion, and lowering the concentration in the receptor (Hewitt et al., 2020). Pollutants from road traffic have a negative effect on urban dwellers, especially pedestrians. The real-time deposition of particular matter from breathing is higher in pedestrians than those taking public transport or driving a car (Kumar et al., 2018). Vegetation can keep pedestrians from being exposed to air pollution by forming a barrier between them and the road (McNabola, 2010). The structure of vegetative barriers must consider the geographical features by the architectural environment. Vegetative barriers can reduce the concentration of air pollution right behind them by half (Al-Dabbous and Kumar, 2014; Lin et al., 2016). GAL (Greater London Authority) emphasized that vegetation can control dispersion in urban streets and can be used to control the flow and distribution of pollutants, and thus adequate green infrastructure in adequate places can reduce exposure to air pollution (Johnston and Newton, 2004).

The flow of air changes depending on the road width and building height in an outdoor space of a city. Trees and vegetation control the air current and speed, thereby affecting air quality improvement by dispersion and deposition. In a structure where buildings are tall and roads are narrow, big trees may rather deteriorate air quality by making it difficult to exchange fresh air with contaminated air. Therefore, this kind of space needs vertical green infrastructure that can increase deposition without disturbing dispersion. Moreover, in a structure where roads are wide, pedestrians are directly exposed to the pollutants from the road; thus, it is necessary to create a vertical greening system between the road and the pedestrians (Kumar et al., 2019).

Among green infrastructure, vertical greening can be classified into living hedges, green facades, and vertical green walls. A living hedge is the form of a wall made with densely planted trees grown up to a certain height. As they grow longer, the branches adjacent to the ground surface may die, resulting in holes in the tree walls. Therefore, to maintain an even green wall up to a certain height, a green façade in which the climbing plants can grow along the wall and a living wall with a growth system for even growth of climbing plants along the surface can be used (Manso and Castro-Gomes, 2015). A green façade is formed by having the plants climb or hang from the wall. The plant may grow above the vertical surface or below the vertical surface when hanging from a certain height. Depending on the species, the plant may climb the wall itself by adhesive disks, while some species can grow through a vertical supporting structure. Adequate species must be chosen among climbing plants. In the living wall system, plants quickly cover the surface of a big wall and grow evenly along the vertical surface, and various plants can be included. However, this method must include systems such as growing containers, supporting elements, and irrigation and drainage facilities for plant growth. It is necessary to decide on adequate greening methods and plants for application depending on the surrounding conditions of vertical green infrastructure.

Previous studies discovered that covering noise barrier walls by the road with vegetation reduces the concentration of ultrafine particles (Bowker et al., 20017; Baldauf et al., 2016). Some modeling studies reported that walls where ivy or other companion plants grow can improve the local air quality. Linear green infrastructure can be established by covering the vertical surfaces including soundproof walls along the main roads with vegetation (Pugh, et al., 2012; Sternberg et al., 2010; Ottelé et al., 2010). This green infrastructure can contribute to reducing air pollutants including particulate matter, urban heat island effects, and alleviation of climate change with carbon storage.

This study was conducted to assess the particulate matter reduction potential of climbing plants that can be applied to green walls including noise barrier walls to reduce air pollution and provide plant data to create green infrastructure. This study provided research methods to quantitatively identify the particulate matter reduction potential of plants, and the results can be used as the basic data for choosing the plants for greening each type of wall.

\section{Research Methods}

\section{Plants}

This study suggests green wall plants to reduce particulate matter in the atmosphere and establish linear green 
infrastructure. To assess the particulate matter reduction potential of green wall plants, we selected plants (Table 1) that are commonly used and easy to get in everyday life among those recommended by a study on green walls (Moon, 2013). We prepared five plants in the same size and volume and used them alternately in each experiment, after which we wiped the leaves and removed the sample so that it does not affect the next experiment.

\section{Methods}

The particulate matter reduction potential of plants was measured in an indoor lab to control the outdoor environmental factors. The experiment was conducted by measuring the changes in particulate matter concentration after putting scattered particulate matter in the experimental chamber that contains the plants. A closed chamber was created with a volume of $1 \mathrm{~m}^{3}$ (width $0.9 \mathrm{~m} \times$ length $0.86 \mathrm{~m} \times$ height $1.3 \mathrm{~m}$ ) for the experiment (Fig. 1). The experimental

Table 1. List of plant species used in the study

\begin{tabular}{lll}
\hline \multicolumn{1}{c}{ Scientific name } & Type of vine & \multicolumn{1}{c}{$\begin{array}{c}\text { Seasonal } \\
\text { properties }\end{array}$} \\
\hline Actinidia arguta & Stem tendril & Deciduous \\
Parthenocissus tricuspidata & Adhesive disc & Deciduous \\
Trachelospermum asiaticum & Adhesive disc & Evergreen \\
Hedera rhombea & Adhesive disc & Evergreen \\
Passiflora caerulea & Tendril & Evergreen \\
Lonicera japonica & Stem tendril & Semi Deciduous \\
Euonymus fortunei & Adhesive disc & Evergreen \\
Stauntonia hexaphylla & Stem tendril & Evergreen \\
\hline
\end{tabular}

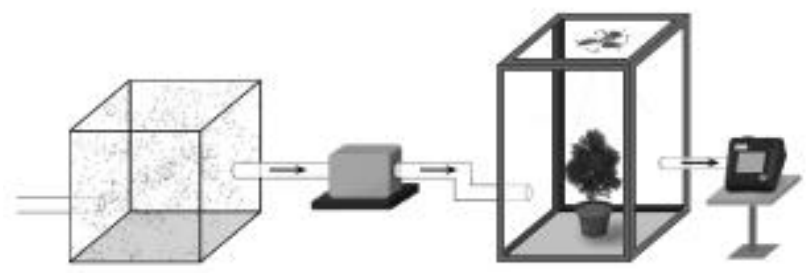

Fig. 1. Schematic diagram of an experimental set up to study. chamber is made with glass to eliminate the impact of electrostatic force and completely sealed with stainless steel and adhesive. A fan is added to the top of the chamber so that the injected particulate matter is mixed well with the air within the chamber. We added a hole on the left to put the sensor to measure particulate matter concentration, and a hole on the other side to inject particulate matter. All holes were closed with a rubber stopper to prevent leakage of particulate matter during the experiment.

JIS TEST POWDER, CLASS 11(JIS Z 8901) is used as the sample of the particulate matter used in the experiment. The chemical composition of the sample is as shown in Table 2, and the particle density is $2.9-3.1 \mathrm{~g} \cdot \mathrm{cm}^{3}$. We put in the particulate matter sample $(3 \mathrm{~g})$ in the acrylic chamber $(1.0 \times 1.0 \times 1.2 \mathrm{~m})$ and injected air with an air pump so that the sample is mixed with the air. The scattered particulate matter is left in the chamber for 3 hours and used in the experiment after the heavy particles are settled.

We used a pump $\left(5 \mathrm{~Hz}: 2.38 \mathrm{~L} \cdot \mathrm{s}^{-1}\right)$ to inject particulate matter scattered in the acrylic chamber into the experimental chamber that contains the plant so that the concentration of ultrafine particles (PM 2.5) became $300 \mu \mathrm{g}$. We opened the air outlet on the other side when injecting the particulate matter to maintain the air pressure within the chamber, and then closed it immediately after injection. We also operated the fan right after injecting the particulate matter so that it is evenly mixed within the chamber. The experiment was conducted by putting one type of plant in the chamber, and the experiment was conducted on the empty chamber in the same way, using it as a control plot. Each plant was experimented repeatedly for 6 times. The temperature of the lab with the chamber was maintained at $22^{\circ} \mathrm{C}$, and lighting was installed in the chamber to maintain the amount of light at $20.25 \mu \mathrm{mol} \cdot \mathrm{m}^{-2} \cdot \mathrm{s}^{-1}$.

\section{Measurement and analysis}

Particulate matter concentration in the chamber was measured using a particulate matter measuring device (Model

Table 2. Chemical properties of particulate matter used in this study

\begin{tabular}{cccccccc}
\hline Chemical composition & $\mathrm{SiO}_{2}$ & $\mathrm{Fe}_{2} \mathrm{O}_{3}$ & $\mathrm{Al}_{2} \mathrm{O}_{3}$ & $\mathrm{CaO}$ & $\mathrm{MgO}$ & $\mathrm{TiO}_{2}$ & Ignition Loss \\
\hline$\%$ (mass) & $34-40$ & $17-23$ & $26-32$ & $0-3$ & $0-7$ & $0-4$ & $0-4$ \\
\hline
\end{tabular}


8533, TSI Inc., USA). Sampling was done by inhaling air for 4 minutes at the flow velocity of $3 \mathrm{~L} \cdot \mathrm{min}^{-1}$. particulate matter is adsorbed on the inner surface of the chamber by gravitational sedimentation and diffusion regardless of the plant's existence. This study analyzed the reduction potential based on concentration variance in the experimental chamber with the plant and the empty chamber (control plot). The particulate matter reduction level by the plant can be obtained by subtracting the amount adsorbed on the chamber $(\mathrm{Ve})$ from the variance of the experimental chamber $(\mathrm{Vp})$. The variance of the chamber $(\mathrm{V})$ is calculated by subtracting concentration after certain time $\mathrm{t}(\mathrm{Ct})$ from the concentration in the initial chamber $\left(\mathrm{C}_{0}\right)$. The amount adsorbed on the chamber was obtained by using the measurement $(\mathrm{Ve})$ of the empty chamber, which is the control plot. To compare the reduction potential (RAP) of each plant, we divided the difference between the experimental chamber and empty chamber $(\mathrm{Vp}-\mathrm{Ve})$ by the leaf area (LA) of each plant. The basic equations for particulate matter concentration analysis are as follows (Jeong et al., 2020).

$$
\begin{aligned}
& \mathrm{V}=\mathrm{C}_{0}-\mathrm{Ct} \\
& \mathrm{RAp}=(\mathrm{Vp}-\mathrm{Ve}) / \mathrm{LA}
\end{aligned}
$$

\section{Statistical analysis}

SPSS 24 was used in the statistical analysis to test the statistical significance of the results. Means were calculated by descriptive statistics to analyze the particulate matter concentration by plant species and time. To identify the particulate matter reduction level by plant species over time, time was used as the independent variable and reduction level as the dependent variable, and the particulate matter reduction speed was analyzed at 2-hour intervals through using the linear regression equation. The reduction level at 2-hour intervals was calculated on the leaf area, and the reduction level by plant species was comparatively analyzed by one-way ANOVA. Pearson correlation analysis was conducted to analyze the relationship between leaf characteristics and reduction level.

\section{Results and Discussion}

\section{Particulate matter reduction potential of plants for green walls}

\section{Particulate matter reduction potential of plants}

As a result of injecting particulate matter into the chamber with the plant and the empty chamber (control plot) and monitoring the changes in the concentration of PM1, PM2.5, and PM10 over time, it was found that all chambers similarly showed a decrease in particulate matter concentration over time. PM1 concentration decreased in the chamber with plants by $11.8 \%$ and $9.4 \%$ after 2 hours and 4 hours compared to the control plot. PM2.5 also decreased by $13.3 \%$ and $10.6 \%$, and PM10 by $14.8 \%$ and $10.8 \%$ (Fig. 2). The chamber with the plant had higher reduction level than the control plot, which explains that plant existence affects the reduction speed of particulate matter in the air. This is because the plant takes up a certain volume of the chamber, thereby reducing the distance between the dust particles and adsorbable surface (Ryu et al., 2019). As the fine particulate matter floats in the chamber, some sink and some is adsorbed on the plant leaves, thereby reducing particulate matter concentration within the chamber. The reduction rate of particulate matter decreases in the order of PM10 > PM2.5 > PM1. This is because, assuming that the particles of particulate matter are in globular shape, the sedimentation velocity by gravity is affected by the particle diameter. Thus, heavier particles sink more quickly,

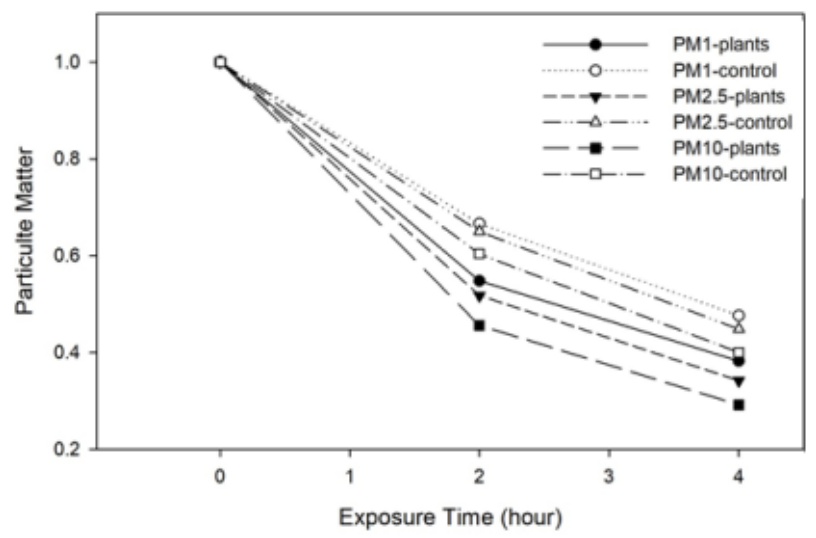

Fig. 2. Change in the concentration of PM in a plant chamber and an empty chamber. 
whereas lighter particles float in the air relatively longer.

\section{Particulate matter reduction potential of plants by exposure time}

To identify the particulate matter reduction potential of plants depending on particulate matter exposure time, we analyzed the slope of the linear regression equation that can predict particulate matter reduction speed at 2-hour intervals. Comparing the particulate matter reduction speed of plants with the control plot, the reduction speed was higher in the plant chamber up to 2 hours after injecting particulate matter, but after that, the reduction speed was higher in the control plot (Table 3). This is because the particulate matter in the air sinks right after injection and is adsorbed on the plant leaves and stems with closer deposition distance, thereby rapidly reducing the concentration of particulate matter. However, after some time, the receptive capacity in which the plant can adsorb particulate matter decreases. There is a difference in absolute slope (speed) depending on the particles, but the difference in the reduc- tion speed between the plant chamber and the control plot showed a similar tendency. However, the particulate matter sedimentation velocity is rapidly higher in bigger particles, thereby having a bigger slope. This tendency was found similarly in individual plants, but $S$. hexaphylla and $P$. caerulea showed continuously higher particulate matter reduction speed in the plant chamber than the control plot even when the exposure time continued. $S$. hexaphylla has relatively bigger leaves than other plants and thus have bigger areas to adsorb the particulate matter, thereby having enough receptive capacity.

By particle, PM1 with small particles showed the biggest difference between the experimental plot and control plot for $T$. asiaticum, followed by $P$. tricuspidate and A. arguta. In other words, PM1 with small particles had the biggest reduction effect in $T$. asiaticum at the initial point of exposure. On the other hand, the reduction speed of the control plot after 2 hours was also high in T. asiaticum, which is related to the receptive capacity of $T$. asiaticum with smallest leaves, and PM2.5 and PM10 also showed a similar tendency.

Table 3. Analysis of the regression coefficient of the reduction potential evaluation function according to the exposure time of PM

\begin{tabular}{|c|c|c|c|c|c|c|c|}
\hline \multirow{2}{*}{ Plants } & \multirow{2}{*}{ Treatment } & \multicolumn{2}{|c|}{ PM1 } & \multicolumn{2}{|c|}{ PM2.5 } & \multicolumn{2}{|c|}{ PM10 } \\
\hline & & Oh-2H & $2 \mathrm{H}-4 \mathrm{H}$ & $0 \mathrm{H}-2 \mathrm{H}$ & $2 \mathrm{H}-4 \mathrm{H}$ & $0 \mathrm{H}-2 \mathrm{H}$ & $2 \mathrm{H}-4 \mathrm{H}$ \\
\hline \multirow{2}{*}{ Total } & experiment & -54.4 & -20.2 & -72.4 & -26.5 & -98.0 & -29.4 \\
\hline & control & -39.9 & -23.5 & -52.1 & -31.0 & -69.1 & -36.4 \\
\hline \multirow{2}{*}{ A. arguta } & experiment & -52.6 & -20.9 & -71.2 & -26.6 & -93.3 & -29.0 \\
\hline & control & -34.5 & -24.5 & -44.7 & -31.0 & -57.3 & -36.3 \\
\hline \multirow{2}{*}{ P. tricuspidata } & experiment & -62.0 & -20.8 & -82.7 & -26.9 & -107.4 & -29.0 \\
\hline & control & -43.4 & -22.6 & -56.6 & -29.6 & -77.3 & -35.2 \\
\hline \multirow{2}{*}{ T. asiaticum } & experiment & -60.8 & -12.5 & -80.5 & -17.7 & -115.4 & -19.6 \\
\hline & control & -39.2 & -24.5 & -51.0 & -31.0 & -67.0 & -36.3 \\
\hline \multirow{2}{*}{ S. hexaphylla } & experiment & -49.9 & -22.6 & -67.1 & -29.9 & -88.4 & -32.9 \\
\hline & control & -36.3 & -21.3 & -48.1 & -27.6 & -59.9 & -31.4 \\
\hline \multirow{2}{*}{ H. rhombea } & experiment & -51.2 & -23.1 & -67.4 & -30.0 & -91.0 & -33.5 \\
\hline & control & -38.6 & -25.9 & -49.9 & -36.2 & -68.5 & -43.0 \\
\hline \multirow{2}{*}{ P. caerulea } & experiment & -54.8 & -16.5 & -72.0 & -23.3 & -98.5 & -27.0 \\
\hline & control & -45.0 & -17.0 & -59.0 & -22.3 & -76.8 & -26.2 \\
\hline \multirow{2}{*}{ L. japonica } & experiment & -53.3 & -20.9 & -69.9 & -26.9 & -92.4 & -29.8 \\
\hline & control & -39.3 & -24.0 & -51.0 & -33.7 & -69.1 & -40.2 \\
\hline \multirow{2}{*}{ E. fortunei } & experiment & -50.8 & -22.5 & -68.2 & -29.6 & -97.7 & -33.6 \\
\hline & control & -40.6 & -25.3 & -53.3 & -32.8 & -70.2 & -38.7 \\
\hline
\end{tabular}




\section{Particulate matter reduction potential by plant}

The experiment was conducted by selecting plants with similar sizes, volumes, and greenness index, but they have different conditions such as the number of leaves or leaf area. Thus, individual species can be compared by time flow, but different species cannot be compared among them. Therefore, to compare the particulate matter reduction potential of plants, we calculated and analyzed the particulate matter reduction ability based on unit leaf area (Table 4). The plant with the biggest PM1 reduction potential 2 hours after exposure was A. arguta followed by $P$. tricuspidate, and the reduction level was 79.0 ug and 70.2 ug based on unit leaf area. The plant with the biggest PM2.5 reduction potential was $A$. arguta at $120.8 \mathrm{ug}$, followed by $P$. tricuspidata, E. fortunei, and T. asiaticum at 98.5, 96.6, and 91.4 ug. The PM10 reduction potential was highest in E. fortunei at $177.4 \mathrm{ug}$, followed by T. asiaticum 102.0 ug, A. arguta 111.6 ug, and P. tricuspidata 90.2 ug, showing a slight difference in the order of plants for PM1 and PM2.5 reduction ability, but a certain level of difference in the order of PM10 reduction ability. In the study by Chen et al. (2017) who investigated the adsorption of particulate matter on 24 species of woody plants, $P$. tricuspidate was effective in PM2.5 and PM0.2 accumulation. A study by Kwon et al. (2020) on 12 species of woody plants showed high reduction effect in $A$. arguta and $P$. tricuspidata. There was almost no difference between after
2 hours and after 4 hours in terms of the ranking for reduction potential by particle, but in PM10, P. caerulea that was ranked 7 th in reduction potential after 2 hours was ranked 3rd after 4 hours. In all species except $S$. hexaphylla and $P$. caerulea, the reduction potential was relativley lower after 4 hours compared to after 2 hours. In other words, $S$. hexaphylla and P. caerulea show high reduction potential when they are exposed longer to particulate matter. This implies that, since $S$. hexaphylla has relatively big leaves, they have higher receptive capacity to adsorb particulate matter and thus the particulate matter reduction potential increases over time compared to the initial point of exposure. While other species have ovate/elliptic leaves, $P$. caerulea has digitated leaves and thus has a remarkably higher shape index than other plants. This difference due to leaf shape affects dispersion of particulate matter, hindering the adsorption on the leaf surface at the initial point of exposure, and thereby increasing reduction potential over time. As a result of conducting one-way ANOVA to analyze the particulate matter reduction potential of plants, there was no statistically significant difference in all particles.

\section{Particulate matter reduction potential by plant leaf characteristics}

As a result of analyzing stoma length and stoma area

Table 4. PM reduction of plants based on leaf area

\begin{tabular}{|c|c|c|c|c|c|c|c|c|c|c|c|c|}
\hline \multirow{3}{*}{ Plant } & \multicolumn{4}{|c|}{ PM1 } & \multicolumn{4}{|c|}{ PM2.5 } & \multicolumn{4}{|c|}{ PM10 } \\
\hline & \multicolumn{2}{|c|}{$2 \mathrm{H}$} & \multicolumn{2}{|c|}{$4 \mathrm{H}$} & \multicolumn{2}{|c|}{$2 \mathrm{H}$} & \multicolumn{2}{|c|}{$4 \mathrm{H}$} & \multicolumn{2}{|c|}{$2 \mathrm{H}$} & \multicolumn{2}{|c|}{$4 \mathrm{H}$} \\
\hline & Mean & $\mathrm{SD}$ & Mean & SD & Mean & SD & Mean & $\mathrm{SD}$ & Mean & $\mathrm{SD}$ & Mean & SD \\
\hline A. arguta & 79.0 & 29.7 & 57.8 & 35.6 & 120.8 & 26.3 & 92.9 & 43.1 & 154.7 & 69.6 & 111.6 & 77.9 \\
\hline P. tricuspidata & 70.2 & 16.5 & 63.4 & 17.6 & 98.5 & 20.9 & 88.3 & 19.6 & 113.6 & 40.8 & 90.2 & 38.6 \\
\hline T. asiaticum & 69.7 & 28.7 & 31.0 & 32.1 & 96.1 & 24.5 & 52.2 & 34.7 & 155.9 & 40.9 & 102.0 & 46.0 \\
\hline S. hexaphylla & 35.4 & 19.4 & 38.8 & 22.3 & 49.4 & 25.6 & 55.4 & 31.4 & 74.2 & 46.3 & 78.1 & 55.6 \\
\hline H. rhombea & 57.3 & 44.1 & 44.5 & 25.2 & 79.5 & 56.0 & 51.4 & 38.9 & 102.3 & 78.4 & 59.1 & 49.9 \\
\hline P. caerulea & 39.2 & 17.0 & 43.6 & 28.3 & 52.0 & 20.0 & 63.2 & 35.5 & 90.4 & 47.7 & 102.8 & 44.1 \\
\hline L. japonica & 58.3 & 32.5 & 45.6 & 25.5 & 79.2 & 41.0 & 50.8 & 22.0 & 97.1 & 91.6 & 53.8 & 73.9 \\
\hline E. fortunei & 65.6 & 54.7 & 47.5 & 27.5 & 96.6 & 58.5 & 75.5 & 30.5 & 177.4 & 67.2 & 144.7 & 47.3 \\
\hline Total & 59.3 & 33.1 & 46.5 & 26.5 & 84.0 & 40.7 & 66.2 & 33.9 & 120.7 & 67.0 & 92.8 & 57.8 \\
\hline $\mathrm{F}$ & \multicolumn{2}{|c|}{1.082} & \multicolumn{2}{|c|}{0.698} & \multicolumn{2}{|c|}{2.142} & \multicolumn{2}{|c|}{1.371} & \multicolumn{2}{|c|}{1.740} & \multicolumn{2}{|c|}{1.405} \\
\hline P-value & \multicolumn{2}{|c|}{0.397} & \multicolumn{2}{|c|}{0.673} & \multicolumn{2}{|c|}{0.067} & \multicolumn{2}{|c|}{0.251} & \multicolumn{2}{|c|}{0.135} & \multicolumn{2}{|c|}{0.238} \\
\hline
\end{tabular}


in the structural aspect of plant leaf characteristics, it was found that stoma length was minimum $8.36 \mu \mathrm{m}$, maximum $19.96 \mu \mathrm{m}$, and average $12.9 \mu \mathrm{m}$, and it was longest in $P$. tricuspidata, followed by A. arguta, E. fortunei, and $H$. rhombea, while it was shortest in $P$. caerulea and $L$. japonica. Stoma area was minimum $20.0 \mu \mathrm{m}^{2}$, maximum $528.0 \mu \mathrm{m}^{2}$, and average $186.9 \mu \mathrm{m}^{2}$, and it was biggest in E. fortunei, followed by P. tricuspidata, $H$. rhombea, and A. arguta, and smallest in $P$. caerulea. stoma length and stoma area have the Pearson correlation coefficient of $0.507(p=<.001)$ and are in a statistically significant positive relationship. We analyzed the shape index by dividing the leaf area by circumference to identify the morphological features. The index of shape closer to 1 indicates that the leaf is closer to a circular shape, whereas bigger numbers indicate that the leaf has a complicated shape. The shape index of the 7 species of plants except $P$. caerulea was minimum 1.13 and maximum 1.31 , generally showing a simple circular shape, but the index of $P$. caerulea was 3.83, showing an irregular, complex shape. As a result of analyzing the area of one leaf to identify leaf size, $T$. asiaticum was smallest at $2.3 \mathrm{~cm}^{2}$ and $S$. hexaphylla was biggest at $29.3 \mathrm{~cm}^{2}$. By analyzing fresh weight and leaf area that are the ecological features of leaves, we discovered that while we chose plants with visually similar volume, fresh weight ranged from 54.02 to $163.80 \mathrm{mg}$ and leaf area from 1,670.6 to 3914.9 , thereby showing a statistically significant difference by plant (Table 5 ).
We conducted a correlation analysis to identify the relationship between the leaf characteristics such as structural, morphological, and ecological characteristics and the reduction potential (Table 6). Although there is a difference depending on the particle, stoma length showed a positive correlation with particulate matter potential after 2 hours in all particles. In other words, stoma length and particulate matter potential change toward the same tendency. Previous studies also explained that stoma size and stoma density are important elements that control particulate matter accumulation (Abbruzzese et al., 2009), but failed to explain the consistent relationship between stoma size and fine matter accumulated on the leaf surface (Simon, 2014; Liang, et al., 2016). The inflow of particulate matter through stomas may vary depending on relative humidity, photosynthesis, and plant growth, which is why continuous research is needed (Mohan, 2016; Farmer, 1993; Rai et al., 2010). The PM2.5 reduction potential and leaf area after 2 hours showed a statistically significant correlation, but the correlation was negative. In other words, the potential and leaf area after 2 hours of exposure have a negative effect. According to Weerakkodyet al. (2017) who investigated the ability of 17 plant species used on green walls to capture particulate matter, the particulate matter adsorption effect was greater for plant species with smaller leaves. The reduction potential after 4 hours of exposure to PM10 has a statistically significant positive correlation with fresh weight and weight per leaf. In other words, heavier leaves

Table 5. Analysis of leaf characteristics

\begin{tabular}{|c|c|c|c|c|c|c|}
\hline Plant & $\begin{array}{l}\text { Length of stoma } \\
\qquad(\mu \mathrm{m})\end{array}$ & $\begin{array}{l}\text { Area of stoma } \\
\left(\mu \mathrm{m}^{2}\right)\end{array}$ & $\begin{array}{c}\text { Index of shape } \\
(\mathrm{S} / \mathrm{L})\end{array}$ & $\begin{array}{l}\text { Leaf size } \\
\qquad\left(\mathrm{cm}^{2}\right)\end{array}$ & $\begin{array}{c}\text { Fresh weight } \\
\text { (mg) }\end{array}$ & $\begin{array}{l}\text { Leaf area } \\
\qquad\left(\mathrm{cm}^{2}\right)\end{array}$ \\
\hline A. arguta & $17.2 \pm 3.9 \mathrm{~b}$ & $185.4 \pm 26.4 \mathrm{~d}$ & $1.23 \pm 0.05 \mathrm{bcd}$ & $12.3 \pm 1.6 \quad \mathrm{~b}$ & $73.7 \pm 0.02 \mathrm{~g}$ & $1,674.6 \pm 2.7 \mathrm{~h}$ \\
\hline P. tricuspidata & $19.9 \pm 1.7 \mathrm{a}$ & $281.8 \pm 57.4 \mathrm{~b}$ & $1.30 \pm 0.09 \mathrm{~b}$ & $8.6 \pm 1.1 \quad \mathrm{c}$ & $91.5 \pm 0.02 \mathrm{e}$ & $2,641.1 \pm 6.8 \quad \mathrm{c}$ \\
\hline T. asiaticum & $10.4 \pm 1.2 \mathrm{~d}$ & $78.6 \pm 19.6 \mathrm{f}$ & $1.13 \pm 0.04 \mathrm{~d}$ & $2.3 \pm 0.9 \quad \mathrm{~d}$ & $127.4 \pm 0.03 \mathrm{c}$ & $3,085.2 \pm 47.1 \mathrm{~b}$ \\
\hline S. hexaphylla & $10.9 \pm 1.2 \mathrm{~d}$ & $125.6 \pm 33.6 \mathrm{e}$ & $1.31 \pm 0.04 \mathrm{~b}$ & $29.8 \pm 12.0 \mathrm{a}$ & $82.5 \pm 4.85 \mathrm{f}$ & $3,842.9 \pm 47.2 \mathrm{a}$ \\
\hline H. rhombea & $13.7 \pm 2.8 \mathrm{c}$ & $221.0 \pm 31.7 \mathrm{c}$ & $1.28 \pm 0.07 \mathrm{bc}$ & $12.6 \pm 6.0 \quad b$ & $93.3 \pm 0.66 \mathrm{~d}$ & $2,176.1 \pm 6.7 \quad \mathrm{~g}$ \\
\hline P. caerulea & $8.4 \pm 1.9 \mathrm{e}$ & $28.6 \pm 6.1 \mathrm{~g}$ & $3.83 \pm 0.38 \mathrm{a}$ & $14.9 \pm 3.1 \quad b$ & $151.6 \pm 0.66 \mathrm{~b}$ & $2,474.9 \pm 7.3 \mathrm{e}$ \\
\hline L. japonica & $8.4 \pm 1.9 \mathrm{e}$ & $117.4 \pm 14.8 \mathrm{e}$ & $1.19 \pm 0.07 \mathrm{~cd}$ & $5.5 \pm 1.3 \mathrm{~cd}$ & $55.0 \pm 0.73 \mathrm{~h}$ & $2,398.9 \pm 7.3 \quad f$ \\
\hline E. fortunei & $14.2 \pm 0.9 \mathrm{c}$ & $457.0 \pm 55.1 \mathrm{a}$ & $1.14 \pm 0.03 \mathrm{~d}$ & $5.2 \pm 1.1 \mathrm{~cd}$ & $158.8 \pm 3.34 \mathrm{a}$ & $2,598.9 \pm 7.3 \mathrm{~d}$ \\
\hline Mean & $12.9 \pm 4.4$ & $186.9 \pm 131.7$ & $1.55 \pm 0.88$ & $11.4 \pm 9.4$ & $104.2 \pm 35.3$ & $2,611.6 \pm 602.3$ \\
\hline $\begin{array}{c}\mathrm{F} \\
\text { (P-value) }\end{array}$ & $\begin{array}{l}55.945 \\
(.000)\end{array}$ & $\begin{array}{c}224.874 \\
(.000)\end{array}$ & $\begin{array}{c}611.507 \\
(.000)\end{array}$ & $\begin{array}{l}44.711 \\
(.000)\end{array}$ & $\begin{array}{c}4693.387 \\
(.000)\end{array}$ & $\begin{array}{c}10486.207 \\
(.000)\end{array}$ \\
\hline
\end{tabular}


Table 6. Correlation analysis between leaf characteristics of plants and PM potential reduction

\begin{tabular}{|c|c|c|c|c|c|c|}
\hline \multirow{2}{*}{$\begin{array}{c}\text { Pearson correlation } \\
\text { coefficient }\end{array}$} & \multicolumn{2}{|c|}{ PM1 } & \multicolumn{2}{|c|}{ PM2.5 } & \multicolumn{2}{|c|}{ PM10 } \\
\hline & $\begin{array}{c}\text { Potential in } 2 \\
\text { hours }\end{array}$ & $\begin{array}{c}\text { Potential in } 4 \\
\text { hours }\end{array}$ & $\begin{array}{c}\text { Potential in } 2 \\
\text { hours }\end{array}$ & $\begin{array}{c}\text { Potential in } 4 \\
\text { hours }\end{array}$ & $\begin{array}{c}\text { Potential in } 2 \\
\text { hours }\end{array}$ & $\begin{array}{c}\text { Potential in } 4 \\
\text { hours }\end{array}$ \\
\hline Length of stoma & $0.343^{*}$ & 0.247 & $0.427 * *$ & $0.338^{*}$ & $0.318^{*}$ & 0.225 \\
\hline Area of stoma & 0.149 & 0.146 & 0.219 & 0.19 & 0.254 & 0.201 \\
\hline Leaf size & -0.237 & -0.085 & -0.287 & -0.093 & -0.292 & -0.135 \\
\hline Index of shape & -0.212 & -0.042 & -0.28 & -0.048 & -0.161 & 0.05 \\
\hline Fresh weight & -0.057 & -0.112 & -0.072 & 0.003 & 0.203 & $0.335^{*}$ \\
\hline Leaf area & -0.247 & -0.197 & $-0.329 *$ & -0.21 & -0.178 & -0.037 \\
\hline Fresh weight/Leaf area & 0.052 & 0.004 & 0.085 & 0.129 & 0.263 & $0.339 *$ \\
\hline
\end{tabular}

Note; *: $P<.05,{ }^{* *}: P<.01$
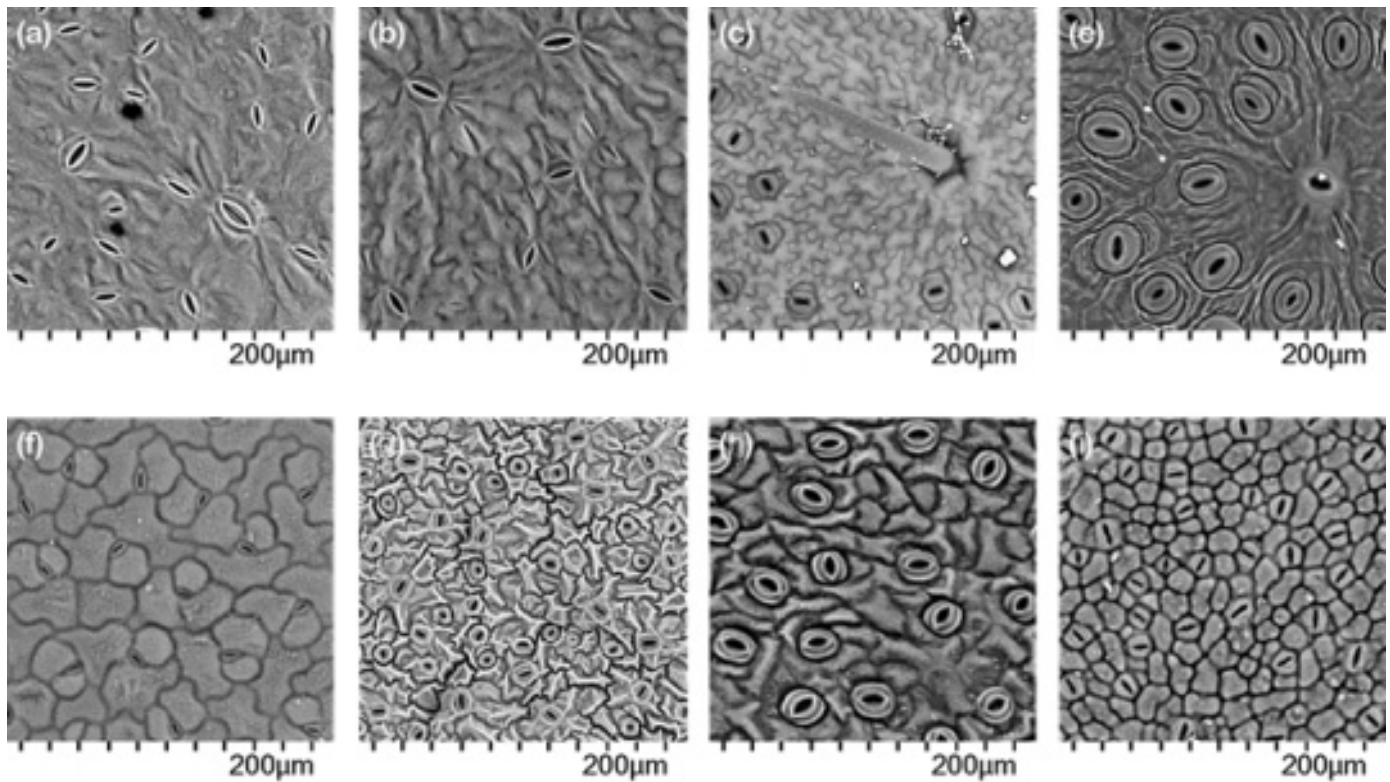

Fig. 3. SEM photomicrograph of adaxial leaf surface (A: A. arguta, B: P. tricuspidata, C: T. asiaticum, D: S. hexaphylla, E: H. rhombea, F: P. caerulea, G: L. japonica, H: E. fortunel).

have a positive effect on particulate matter reduction. This indicates that leaf characteristics are related to the particulate matter reduction potential of plants.

The leaf structure is a distinct feature of individual species and affects the plant's capacity to block particulate matter in the air and adsorb particles (Sæbø et al., 2012; Sehmel, 1980; Freer-Smith et al., 1997; Freer-Smith et al., 2014; Wang et al., 2010; Cao et al., 2019). In particular, the hairs on the leaf surface perform the role of holding the adsorbed particulate matter from being desorbed (Chen et al., 2017; Hwang et al., 2011). Therefore, the hairs on leaves are an important feature that affects the particulate matter adsorption effect. Trichomes on the leaf surface have a correlation with the amount of particulate matter adsorbed on the surface (Chen et al., 2017). This study also showed similar results as there were hooked trichomes on the leaf surface of $T$. asiaticum that show the highest particulate matter reduction level (Fig. 3).

\section{Conclusion}

Green infrastructure in the city can serve as a buffer zone to directly block air pollutants. This study identified 
the particulate matter reduction potential of plants with a climbing habit that can be used in creating green walls to prevent pollutants, using vertical green infrastructure.

Compared to the control plot, the plant chamber showed high particulate matter reduction level per hour, and thus plants could contribute to the reduction of particulate matter in the air. In the plant chamber, the reduction speed of particulate matter is high at first, which is reduced over time. Moreover, particulate matter reduction continued in plants with big leaves. In other words, leaf surface adsorption of particulate matter is an important factor of particulate matter concentration reduction. Since the receptive capacity to adsorb particulate matter seems to decrease over time, further research must be conducted on how to maintain the reduction potential of plants. As a result of calculating the particulate matter reduction level based on leaf area, it was found that there was a difference by particle size. A. arguta, P. tricuspidata, T. asiaticum, and E. fortune showed a high reduction effect, whereas $S$. hexaphylla showed a low reduction effect. Fresh weight and particulate matter reduction potential had a positive correlation. Since leaf weight is related to the wax layer, there must also be a study determining the relationship between the wax layer weight and potential. Out of the 8 species, $T$. asiaticum had trichomes on the leaf surface, which affected the reduction of particulate matter.

The significance of this study is that it minimized the variables by analyzing them in the same lab settings with controlled chambers, thereby comparing the potential by plant species. However, since the experiment was conducted in closed chambers, particulate matter concentration decreased unlike the atmospheric environment, but it was possible to quantify the particulate matter reduction level for a certain period of time. The results of this study can be used as the basic data to select the suitable plant species for urban green walls in terms of particulate matter reduction.

\section{References}

Abbruzzese, G., I. Beritognolo, R. Muleo, M. Piazzai, M. Sabatti, G.S. Mugnozza, and E. Kuzminsky. 2009. Leaf morphological plasticity and stomatal conductance in three Populus alba L. genotypes subjected to salt stress. Environ. Exp. Bot. 66(3):381-388. https://doi.org/10.101 6/j.envexpbot.2009.04.008

Abhijith, K.V., P. Kumar, J. Gallagher, A. McNabola, R. Baldauf, F. Pilla, B. Broderick, S. Di Sabatino, and B. Pulvirenti, 2017. Air pollution abatement performances of green infrastructure in open road and built-up street canyon environments - A review. Atmos. Environ. 162:71-86. https://doi.org/10.1016/j.atmosenv.2017.05.014

Al-Dabbous, A.N., and Kumar, P., 2014. The influence of roadside vegetation barriers on airborne nanoparticles and pedestrians exposure under varying wind conditions. Atmos. Environ. 90:113-124. https://doi.org/10.1016/j.at mosenv.2014.03.040

Baldauf, R.W., V. Isakov, P. Deshmukh, A. Venkatram, B. Yang, and K. Zhang, 2016. Influence of solid noise barriers on near-road and on-road air quality. Atmos. Environ. 129:265-276. https://doi.org/10.1016/j.atmosen v.2016.01.025

Bowker, G.E., R. Baldauf, V. Isakov, A. Khlystov, and W. Petersen, 2007. The effects of roadside structures on the transport and dispersion of ultrafine particles from highways. Atmos. Environ. 41(37):8128-8139. https://doi.org/10.1016/j.atmosenv.2007.06.064

Cao Y., F. Li, Y. Wang, Y. Yu, Z. Wang, X. Liu, and K. Ding. 2019. Assisted deposition of PM2.5 from indoor air by ornamental potted plants. Sustain.ability. 11(9):2546-2555. https://doi.org/10.3390/su11092546

Chalvatzaki, E., S. Chatoutsidou, H. Lehtomäki, S. Almeida, K. Eleftheriadis, O. Hänninen, and M. Lazaridis, 2019. Characterization of human health risks from particulate air pollution in selected european cities. Atmosphere. 10(2):96-107. https://doi.org/10.3390/atmos10020096

Chen, L., C. Liu, L. Zhanz, and Z. Zhang.. 2017. Variation in tree species ability to capture and retain airborne fine particulate matter (PM2.5). Sci. Rep. 7:3206. https://doi. org/10.1038/s41598-017-03360-1

Farmer, A.M. 1993. The effects of dust on vegetation-a review. Environ. Pollut. 79, 63-75, https://doi.org/10.10 16/0269-7491(93)90179-r

Freer-Smith P., S. Holloway, and A. Goodman. 1997. The uptake of particulates by an urban woodland: site description and particulate composition. Environ. Pollut. 95(1):27-35. PMID: 15093471. https://doi.org/10.1016/s 
0269-7491(96)00119-4

Freer-Smith, P.H., A.A. El-Khatib, and G. Taylor. 2004. Capture of particulate pollution by trees: A comparison of species typical of semi-arid areas (Ficus nitida and Eucalyptus globulus) with European and North American species. Water Air Soil Pollut. 155:173-187. https://doi.org/10.1023/B:WATE.0000026521.99552.fd

Haase, D., N. Larondelle, E. Andersson, M. Artmann, S. Borgström, J. Breuste, E. Gomez-Baggethun, A. Gren, Z. Hamstead, R. Hansen, N. Kabisch, P. Kremer, J. Langemeyer, E. Rall, T. McPhearson, S. Pauleit, S. Qureshi, N. Schwarz, A. Voigt, D. Wurster., and T. Elmqvist. 2014. A quantitative review of urban ecosystem service assessments: concepts, models, and implementation. Ambio. 43(4):413-433. https://doi.org/10.1007/s13 280-014-0504-0.

Hewitt, C., K. Ashworth, and A. MacKenzie. 2020. Using green infrastructure to improve urban air quality (GI4AQ). Ambio 49: 62-73. https://doi.org/10.1007/s13280-019-0 1164-3

Hussain, M., P. Madl, and A. Khan. 2011. Lung deposition predictions of airborne particles and the emergence of contemporary diseases Part-I. Health 2(2):51-59.

Hwang, H.J., S.J. Yook, and K.H. Ahn. 2011. Experimental investigation of submicron and ultrafine soot particle removal by tree leaves, Atmos. Environ. 45(38): 6987-6994. https://doi.org/10.1016/j.atmosenv.2011.09.019

Jeong N.R., K.J. Kim, J.H. Yoon, S.W. Han, and S.J. You. 2020. Evaluation on the potential of 18 species of indoor plants to reduce particulate matter. J. People Plants Environ. 23(6):637-646. https://doi.org/10.11628/ksppe. 2020.23.6.637

Johnston, J., and J. Newton. 2004. Building Green A Guide to Using Plants on Roofs, Walls and Pavements. Greater London Authority. Available at: https://brightonandhove buildinggreen.files.wordpress.com/2017/07/johnstone-a nd-newton-building-green.pdf (accessed: 13 May 2020).

Kumar, P., A. Druckman, J. Gallagher, B. Gatersleben, S. Allison, T. Eisenman, U. Hoang, S. Hama, A. Tiwari, A. Sharma, K.V. Abhijith, D. Adlakha, A. McNabola, T. Astell-Burt, X. Feng, A.C. Skeldon, S.de. Lusignan, and L. Morawska. 2019. The nexus between air pollution, green infrastructure and human health. Environ Int. 133(Part A):105181. https://doi.org/10.1016/j.envint.20

\subsection{1}

Kumar, P., I. Rivas, A.P. Singh, V.J. Ganesh, M. Ananya, and H.C. Frey. 2018. Dynamics of coarse and fine particle exposure in transport micro environments. NPJ Clim. Atmos. Sci. 1:11. https://doi.org/10.1038/s41612-018-00 $23-\mathrm{y}$

Kwon, K., O. Urrintuya, S.Y. Kim, J.C. Yang, J.W. Sung, and B.J. Park. 2020. Removal potential of particulate matter of 12 woody plant species for landscape planting. J. People Plants Environ. 23(6):647-654. https://doi.org/ 10.11628/ksppe.2020.23.6.647

Li, X.B., Q.C. Lu, S.J. Lu, H.D. He, Z.R. Peng, Y. Gao, and Z.Y. Wang. 2016. The impacts of roadside vegetation barriers on the dispersion of gaseous traffic pollution in urban street canyons. Urban For. Urban Green. 17(1):80-91. https://doi.org/10.1016/j.ufug.2016.03.006

Liang, D., C. Ma, Y.Q. Wang, Y.J. Wang, and Z. Chen-Xi. 2016. Quantifying PM2.5 capture capability of greening trees based on leaf factors analyzing. Environ Sci Pollut Res Int. 23(21):21176-21186. https://doi.org/10.1007/s1 1356-016-7687-9

Lin, M.Y., G. Hagler, R. Baldauf, V. Isakov, H.Y. Lin, and A. Khlystov. 2016. The effects of vegetation barriers on near-road ultrafine particle number and carbon monoxide concentrations. Sci. Total Environ. 553(15): 372-379. https://doi.org/10.1016/j.scitotenv.2016.02.035

Manso, M., and J. Castro-Gomes. 2015. Green wall systems: A review of their characteristics. Renew Sustain Energy Rev. 41:863-871. https://doi.org/10.1016/j.rser.2014.07.203

McNabola, A. 2010. New Directions: Passive control of personal air pollution exposure from traffic emissions in urban street canyons. Atmos. Environ. 44(24):2940-2941. https://doi.org/10.1016/j.atmosenv.2010.04.005

Mohan, S.M. 2016. An overview of particulate dry deposition: measuring methods, deposition velocity and controlling factors. Int. J. Environ. Sci. Technol. 13:387-402. https://doi.org/10.1007/s13762-015-0898-7

Moon, S.. 2013. The development of 3-dimensional greenery system to building structures(pp.71-80). Seoul, Korea: KEITI. Retrieved from https://ecoplus.keiti.re.kr

Oller, A.R., and G. Oberdörster. 2016. Incorporation of dosimetry in the derivation of reference concentrations for ambient or workplace air: A conceptual approach. J. Aerosol Sci. 99:40-45. https://doi.org/10.1016/j.jaeros 


\section{ci.2016.01.015}

Orru, H., K.L. Ebi, and B. Forsberg. 2017. The interplay of climate change and air pollution on health. Curr. Environ. Health Rep. 4(4):504-513. https://doi.org/10.1 007/s40572-017-0168-6

Ortolani, C., and M. Vitale. 2016. The importance of local scale for assessing, monitoring and predicting of air quality in urban areas. Sustain. Cities Soc. 26:150-160. https://doi.org/10.1016/j.scs.2016.06.001

Ottelé, M., H. van Bohemen, and A. Fraaij. 2010. Quantifying the deposition of particulate matter on climber vegetation on living walls. Ecol Eng. 36:154-162. https://doi.org/1 0.1016/j.ecoleng.2009.02.007

Pugh, T., A.R. MacKenzie, J.D. Whyatt, and C.N. Hewitt. 2012. Effectiveness of green infrastructure for improvement of air quality in urban street canyons. Environ. Sci Technol. 46(14):7692-7699. https://doi.org/10.1021/ es300826w

Rai, A., K. Kulshreshtha, P.K. Srivastava, and C.S. Mohanty. 2010. Leaf surface structure alterations due to particulate pollution in some common plants. Environmentalist. 30:18-23, https://doi.org/10.1007/s10669-009-9238-0

Ryu, J.E., J.J. Kim, H.J. Byeon, T.S. Go, and S.J. Lee. 2019. Removal of fine particulate matter (PM2.5) via atmospheric humidity caused by evapotranspiration. Environ. Pollut. 245:253-259. https://doi.org/10.1016/j. envpol.2018.11.004

Sæbø, A., R. Popek, B. Nawrot, H.M. Hanslin, H. Gawronska, and S.W. Gawronski. 2012. Plant species differences in particulate matter accumulation on leaf surfaces. Sci Total Environ. 427-428(15):347-354. https://doi.org/10. 1016/j.scitotenv.2012.03.084

Sehmel, G.A. 1980. Particle and gas dry deposition: A review. Atmos. Environ. 14(9):983-1011. https://doi.org/10.101 6/0004-6981(80)90031-1

Simon E., E. Baranyai, M. Braun, C. Cserháti, I. Fábián, and B. Tóthmérész. Elemental concentrations in deposited dust on leaves along an urbanization gradient. Sci. Total Environ. 2014. 490(15):514-20. https://doi.org/10.1016/ j.scitotenv.2014.05.028

Sternberg T., H. Viles, A. Cathersides, and M. Edwards. 2010. Dust particulate absorption by ivy (Hedera helix L) on historic walls in urban environments. Sci. Total Environ. 409(1):162-168. https://doi.org/10.1016/j.scitot env.2010.09.022

Wang, H., H. Shi, and Y. Li. 2010. Relationships between leaf surface characteristics and dust-capturing capability of urban greening plant species. J. Appl. Ecol. 21(12): 3077-3082

Weerakkody, U., J.W. Dover, P. Mitchell, K. Reiling. 2017. Particulate matter pollution capture by leaves of seventeen living wall species with special reference to rail-traffic at a metropolitan station. Urban For. Urban Green., 27:173-186. https://doi.org/10.1016/j.ufug.2017. 07.005

WHO 2013. Review of evidence on health aspects of air pollution-REVIHAAP project: technical report. Copenhagen: WHO Regional Office for Europe.

World Health Organization (WHO). Ambient Air Pollution: A Global Assessment of Exposure and Burden of Disease; World Health Organization: Geneva, Switzerland, 2016; 121p, ISBN 9789241511351 . 